\title{
Status of Women in Rural Areas
}

\author{
Radhika Kapur* \\ Pedagogy and Organizational Culture in Nursery Schools, Delhi University, New Delhi, India \\ *Corresponding Author: Radhika Kapur, Pedagogy and Organizational Culture in Nursery Schools, Delhi University, New Delhi, India.
}

Received: April 08, 2019; Published: July 04, 2019

DOI: 10.31080/ASAG.2019.03.0558

\section{Abstract}

In rural communities, the status of women is not effectually recognized. In some communities, they experience discriminatory treatment as compared to their male counterparts. They are deprived of certain rights and opportunities and are required to wholeheartedly dedicate themselves towards the implementation of household responsibilities. In the present existence, there have been implementation of programs and schemes that girls should be regarded as equal to men. Their birth should be appreciated and they should be allowed equal rights and opportunities, particularly with regards to acquisition of education and employment. Changes have come about in the viewpoints and perspectives of rural individuals and they are granting equal status to girls and women. The main areas that have been taken into account in this research paper include, socio-economic status of rural women, labour force participation of women, factors imposing detrimental effects upon status of women, and measures to enhance the status of rural women.
\end{abstract}

Keywords: Enhancement; Labour Force; Responsibilities; Socio-Economic Status; Women

In rural communities, women are experiencing contradictions. On one hand, she is vested with the major responsibility of implementation of household chores, child development, taking care of needs and requirements of elderly family members and so forth. Whereas, on the other hand, she is subjected to various forms of abuse and mistreatment. In some of the rural communities, girls are regarded as liabilities. Their birth is not appreciated and more preference is given to male children. The individuals normally possess the viewpoint that girls should be trained in terms of implementation of household responsibilities and school education is not meant for them. They have to eventually get married, where they will not be able to make use of their academic skills. Whereas, boys are encouraged to get enrolled in schools and acquire education, as it is believed, they would contribute towards promoting well-being of their families and communities, through their educational skills. Hence, in this manner, girls experience discriminatory treatment.

Rural women and girls normally are required to follow the instructions of the male members within the household. In their natal homes, they have to listen to and obey their fathers, in youth, they are required to follow the rules formulated in their marital homes and in old age, they are dependent upon their sons. They are less literate and capable as compared to men. Majority of rural women, not only experience economic poverty, but also information poverty. In some cases, constraints are imposed upon them to express their viewpoints or have a say in the decision making matters. In rural India, the percentage of women, who own land and other productive assets are few. Majority of women are engaged in the agricultural sector, where they are required to carry out manual work. Women mostly are not skilled in terms of use of machines and these are put into operation by men [1].

Socio-economic status of rural women

Women in rural India have been experiencing number of aspects that are imposing detrimental effects upon their socio-economic status. They have been victims of various forms of criminal and violent acts as well, which are proving to be major barriers in their progression. In rural areas, girls are required to contribute in the implementation of household responsibilities. In the present existence, there has been transformations within the viewpoints 
of the individuals and they also aspire to get their girls educated. But prevalence of the conditions of poverty is regarded as a major barrier within the course of acquisition of education. When rural individuals possess limited resources, then they give preference to education among male children. Whereas, girls are trained in terms of implementation of household responsibilities, such as, cleaning, washing, rearing of livestock, fetching water, preparation of meals, taking care of siblings and elderly members of the family, especially when their parents go to work and so forth.

When girls aspire to learn, get enrolled in schools and augment their skills and abilities, but due to certain problems, they are unable to do so, in such cases, their male siblings teach them what they have learned in school. It was observed that among the age group of seven years and above, the literacy rate among the males was found to be 83 percent, whereas, among females, it was found to be 67 percent. Similarly, it was found among rural communities that approximately 4.5 percent of the males and 2.2 percent of the females completed their education to the level of graduation and above. Whereas, in urban areas, the percentage of males, who completed this education is 17 and percentage of females account for $13[2]$.

In the lower socio-economic level of the society, women were engaged in more hazardous manual labour than men. In the agricultural sector, more than half the labourers are women. Still, it is unfortunate that contributions of women are not given recognition and men are considered as bread-winners of the household. The rural women possess the traits of diligence and resourcefulness. They render a whole-hearted contribution in the implementation of various tasks and activities. In spite of their meticulousness, their work is lesser paid outside and unpaid within the house. In various employment settings, their wage is less as compared to men, for the implementation of similar job duties. These aspects signify that they are considered inferior to men. Men normally possess the viewpoint that women should be confined within the household, carry out the household responsibilities and upbringing of the family.

Women participation in development is not considered free from gender discrimination. In the development process, gender bias is considered as the form that alienates women from the mainstream society. The efforts that they perform and the contributions that they make towards the well-being of the society are giving them lesser or no benefits [3]. It is unfortunate and is regarded as a major impediment within the course of progression of not only women, but country as a whole that women are marginalized and are deprived of equal rights and opportunities as compared to their male counterparts. The policies and programs that are formulated, focusing upon development of women put more emphasis upon bringing about improvements in the status of the male members. In rural areas, males are regarded as the ones, who are likely responsible for enhancement of family status. Individuals possess this viewpoint that if they are enrolled in schools or are sent even to urban areas to acquire higher educational qualifications, then they would render an effective contribution towards promoting well-being of their families and communities.

It has been found among rural households, even though they are unable to make provision of education to their children, primarily due to prevalence of the conditions of poverty or any other factor. But they usually send their male children to urban areas to look for better livelihoods opportunities. Girls usually remain in villages, they are trained in terms of implementation of all types of household responsibilities. In addition to household responsibilities, they acquire training in terms of production of various forms of handicrafts, food items, embroideries, knitting, crochet and so forth. In the present existence, rural individuals have recognized the significance of education and are getting their girls enrolled in educational institutions. Therefore, when they acquire efficiency in management of household responsibilities, preparation of meals, production of handicrafts and literacy skills, then they eventually get married.

Earning enhanced livelihoods opportunities is the major priority of the rural individuals. Research has indicated that when women get married and are send to marital homes, then in some cases, they live in their marital homes, along with their in-laws, whereas their husbands move to urban communities to look for better job opportunities. In such cases, women have a dual role to perform. The duality of their roles is recognized in the management of household responsibilities as well as in participation in other tasks and activities. Rural women and girls, normally possess keen interest and desire in the production of handicrafts and artworks. Hence, they are engaged in the production of these items and market them. When they feel they are not able to incur profitability in rural communities, then they migrate to urban communities to market their 
products. But before getting engaged in the production processes, they need to obtain consent from their in-laws.

For rural women, performing dual roles is not a difficult task. When they are involved in the implementation of more than one job, then it is vital for them to put into operation, effective time management skills. For instance, in their marital homes, they have more responsibilities and tasks to carry out, as compared to their natal homes. Since morning until night time, they are required to work meticulously, especially when they are engaged in work. This is one of the most indispensable positive factors of rural women and due to this, they are able to not only supplement family income, but also enhance their status and acquire empowerment opportunities.

\section{Labour Force Participation of Women}

There is an interconnection between the education system and the labour force of women. When women are educated or possess the basic literacy skills of reading, writing and arithmetic, then they are able to acquire employment opportunities, which may be well-paid as compared to the jobs, in which women are engaged, particularly the ones, who are not educated nor possess the basic literacy skills. Within the country, there has been an increase in the demand of labour, both skilled and semi-skilled in urban and rural areas. When women need to look for jobs, it is vital for them to generate awareness in terms of qualifications and experiences required in order to meet the job requirements. In some jobs, employers may require them to possess at least the basic literacy skills, whereas, in other jobs, employers may require them to possess at least senior secondary educational qualification [4].

When participating in the labour force, women experience number of negative as well as positive effects. The negative effects are, the employers may make demands of educational requirements and skills, which may not be possessed by women. Therefore, when they do not possess the required educational qualifications and skills, then they usually experience problems in acquiring employment opportunities. Rural women, who are not educated nor possess the basic literacy skills, usually get engaged in minority jobs, which may include, unskilled manual labour. In rural as well as in urban areas, women get engaged in construction work or perform the tasks of cleaning and sweeping. These are regarded as minority jobs, which may not require them to possess any types of skills. These jobs merely require them to get engaged in manual work.
In most cases, women migrate to urban areas, where they get employed as domestic helpers. In domestic households, they perform the tasks, such as, cleaning, sweeping, washing, or taking care of the needs and requirements of the elderly family members, particularly the ones, who are not ambulatory.

The positive effects that are associated with participation of women in minority jobs within domestic households are numerous, particularly in urban communities. The employers make provision of various items and services that may render an effective contribution in bringing about improvements within their overall quality of lives. These include, making provision of food, clothing and other items, which would be useful to them such as, kitchen appliances, blankets and so forth. Apart from various items, they also provide assistance, such as providing tuition classes to their children free of cost or health care and medical assistance, if they are from the medical background. Hence, through these positive aspects, they are not only able to generate income, but also enhance their skills and abilities.

The individuals employed in the informal sector have less or no formal education. They make use of labour-intensive rather than capital-intensive technology. They are uneducated and unskilled and do not have an easy access to financial capital. In India, nine out of every ten women are employed in the informal sector. The home-based work makes it manageable for women to carry out the family responsibilities as well as render an effectual contribution in the implementation of job duties. Within the country, women, who are employed in the informal sector have inculcated the traits of diligence, resourcefulness and conscientiousness among themselves. The organization of women have taken place through the trade union, i.e. Self-Employed Women's Association (SEWA), which was established in 1972. This organization is regarded as the forum for women in the informal sector, to acquire complete employment and attain social security. The organization makes provision of credit, social security, child care, health care and insurance [4].

Within the formal sector, the rate of employment among the males is higher as compared to women. Therefore, in the informal sector, women are the main labour supply. The informal sector does not make provision of social protection and this augments vulnerability of women. Women in this sector do not require monetary resources to initiate the production process. Since the production processes are labour-intensive, even when the investment made is 
small, it has a high marginal rate of return. It has been observed, within rural households, when women are the heads of the family, then there is a high drop-out rate among children from school, as they are encouraged to participate in the management of household responsibilities as well as jobs. The rate of women is high in the tobacco rolling industry. This industry employs five million workers and 90 percent of them are women. This work is usually home-based and women are able to get their daughters involved as well [4].

In most of the societies in India, social differentiation takes place between genders. Within various forms of employment settings, it was believed by the employers that women are not much capable of performing manual jobs. Manual jobs can be performed appropriately only by men. This viewpoint is regarded as the major cause of discriminatory treatment against women. In recent times, equality of status has been assigned to women, but it is regarded as more legal than existential. This signifies that the status of women is still regarded as subordinate to men. Women are considered primarily as reproducers, although they invented 50 percent of the world's food. Recognition is given to their role as producers and due to this, they have gained significance within society [5].

The employers do possess the viewpoint that men are more capable of performing manual jobs, particularly lifting, loading and so forth. But in rural as well as in urban areas, women too are participating in manual jobs. For instance in the construction of houses and buildings, it has been observed, manually labour jobs are carried out by men as well as women. One of the negative aspects that they experience is, particularly with regards to pay. Men are paid more than women, for the performance of same job duties. This is the major indicator of discriminatory treatment against women. Hence, it is vital for the employers to ensure that women are given equal pay and equal rights and opportunities within the employment settings. This should particularly be in the case of implementation of similar job duties.

\section{Factors imposing detrimental effects upon status of women}

The factors imposing detrimental effects upon the status of women have been identified as follows:

- Poverty: The conditions of poverty within rural communities are not only imposing barriers within the course of enhancement of status of women, but individuals, belonging to all age groups are undergoing unfavourable effects as a result of poverty. In rural India, nearly 45 per- cent of the individuals are living below poverty line. In most cases, they are engaged in minority jobs and are struggling to make ends meet. Under such circumstances, women and children are the ones, who need to undergo detrimental effects to a major extent. Research has indicated that when a household has limited income, then most of it is made use of for providing education, health care and other facilities to the male children. Good quality food is provided to male children and more attention is paid towards their health care needs. On the other hand, proper attention is not paid towards providing adequate diet and nutrition and health care facilities to girls and women. Hence, girls and women experience disadvantages as a result of poverty, more as compared to males.

- Criminal and Violent Acts: Girls and women experience various forms of criminal and violent acts within as well as outside the home. These are, verbal abuse, physical abuse, sexual harassment, exploitation, neglect and discriminatory treatment. The major cause behind inflicting criminal and violent acts upon women is lack of education and preference given to male children. The rural individuals, who regard girls as liabilities, impose criminal and violent acts upon them. They are unable to realize that girls can also render an effective contribution in bringing about well-being of their families and communities, provided, they should be given equal opportunities. Experiencing criminal and violent acts within home and in other places, such as, educational institutions, employment settings, have a major negative effect upon their mind-sets. As a consequence, they feel vulnerable in going out of their homes and remain confined within the house. Research has indicated that criminal and violent acts in schools and training centres have compelled girls to drop out, before their academic skills are honed.

- Economic Exploitation: On the global level, women and girls participate in two-thirds of the world's work and receive only one tenths of the world's income. They form 40 percent of the paid labour force. Women constitute half of the world's population and own only one percent of the world's property. In rural India, their condition is in a deteriorated state in all aspects of social life. They are paid half of three-quarters of the money as compared to their male counterparts, even when they are performing same types of job duties. In the agricultural sector, they perform half of the work, but their work is not given any recognition. On the average, rural women, work for around 15 to 16 hours per day. Women in India earn 25 percent less than men. This depicts that there is existence of gender disparities in determining pay rates [2].

- Educational Deprivation: Apart from discriminatory treatment and neglect, there are number of factors that deprive girls from getting enrolled in schools to augment their educa- 
tional skills and abilities. These are, conditions of poverty, lack of financial resources, lack of interest in studies, shortage of teachers in school, inappropriate teaching-learning methods and instructional strategies, unavailability of proper means of transport, lack of extra-curricular activities in schools, discouraging attitude on the part of the family members, unpleasant home environmental conditions, and implementation of household responsibilities. When girls experience any one or more of these factors, then they experience problems in the acquisition of education. In most cases, they experience challenges in the acquisition of education, due to inability in understanding academic concepts. At home, their parents are not educated and they also are unable to concentrate on their studies. Whereas, in schools as well, when they are unable to clarify their problems, the ultimate outcome is, they do not score well in tests and exams and have to discontinue their education.

- Child Marriage: Child marriage is regarded as a criminal act that imposes negative effects upon the lives of children. Girls are the ones, who suffer to a great extent as compared to boys. It is when marriage takes place of girls and boys, when they are below 18 years of age. Within their natal homes, during the childhood stage, girls are trained in terms of implementation of household chores. It has been found, even when girls are below 10 years of age, they are encouraged to carry out the household chores. When parents feel that they have developed their skills and abilities in an efficient manner, their suitable grooms are found and marriage is arranged. In their marital homes, girls and women are vested with the primary responsibility of carrying out the household chores. Hence, child marriage not only discourages girls from acquisition of education, but also participation in other childhood activities. They merely have to follow the rules and instructions are imposed upon them by their family members.

- $\quad$ Lack of Health Care Facilities: Health care is regarded as the basic requirement for all individuals, irrespective of their gender, class, caste, age, ethnicity and socio-economic background. In rural communities, health care facilities are not in a well-developed state. Individuals experiencing health problems and illnesses are required to travel to distance regions and to urban areas to obtain medical treatment. When the rural individuals do not possess sufficient resources to take care of health care needs and requirements of all family members, then too, girls and women need to undergo deprivation. In such cases, more attention is paid towards health care and well-being of the male members. The major cause of this deprivation is limited financial resources. Another cause is, male children are regarded as the assets of the family. Family members ensure that they get good quality and nutritious meals, and proper medical facilities are provided to them, in case they experience any health problems and illnesses. Whereas, less attention is paid towards making provision of healthy and nutritious meals and health care facilities to girls and women.

- Prohibited from Participation in Decision Making Matters: Decision making is regarded as an integral part of households in all communities. In rural communities too, individuals are required to make decisions in their lives. Decisions can be major or minor. Major decisions are the ones, in which family members may seek ideas and suggestions from others. Whereas, minor decisions are the ones, in which the authority is vested only within the hands of the male members and they do not obtain ideas and suggestions from others. Women and girls are not allowed to have a say in the decision making matters. They are prohibited from giving their ideas and viewpoints and merely have to follow the instructors that have been imposed upon them by their male counterparts. When women possess certain viewpoints and perspectives and want to express them, but the other members of the family are unwilling to listen to them, then they feel despondent and inferiority in their status to a major extent.

- Prohibited from Participation in Other Tasks and Activities: Rural women and girls usually possess the viewpoint that it is necessary for them to get engaged in any kinds of tasks and activities, which would help them to acquire empowerment opportunities. Therefore, when they feel, they are unable to get enrolled in schools to acquire education, then they develop interest in creative and extra-curricular activities. In rural communities, women and girls normally develop interest in extra-curricular activities, such as, singing, music, dance, role plays, production of handicrafts, and artworks and so forth. In some cases, when these aspects are not given attention in their school, then they usually feel disinterested in studies. It has been found that when they express willingness to augment their skills in any one particular area, the family members usually do not give their consent. Hence, they are prohibited from participating in any form of creative and extra-curricular activities. They are able to get engaged in the production of handicrafts and artworks, provided when their family members are involved.

- Unequal Distribution of Wealth and Resources: Women experience discrimination with regards to distribution of wealth and resources. When it is stated, unequal distribution of wealth and resources, it means, male members of the family are given more wealth and resources by their parents. One of the major causes for the prevalence of this disparity is the caste system. This system perpetrates injustice, abuses and exploitation of the vast majorities of the individuals, belonging 
to deprived, marginalized and socio-economically backward sections of the society. In Uttar Pradesh, this problem is still prevalent. It is characterised by large differences in distribution of wealth and resources among men and women [6]. Widows are the ones, who experience deprivation of wealth and resources. When a woman becomes a widow, she was not only prohibited from participation in social, cultural and religious ceremonies, but also were evicted from homes and were denied right to property. Individuals usually possess the viewpoint that widows would bring about bad luck. The widows were required to dress simply in white. They were prohibited from wearing coloured clothes and any ornaments or jewels.

- $\quad$ Limited Visits to Other Places: Women were usually meant to remain confined within the households and restraints were imposed upon their visits to other places as well. When they expressed the desire to make visits to certain places, restraints were imposed upon them, such as, they were required to return home within a certain time frame or were accompanied by other individuals. Girls and women normally express willingness to make visits to their friend's houses, or other religious, social, cultural and other places and so forth. In such cases, they are told, particularly within their marital homes, that when they would complete certain tasks, only then they would be able to go out for leisure purposes. Women are socially and physically suppressed. Low participation of women and girls in education is regarded as the major cause of lesser communication with the outside world. The limited opportunity of women and girls to acquire education is bound to affect their ability to participate in activities and make visits to various places [6].

\section{Measures to enhance the status of rural women}

As it has been understood that women in rural communities are undergoing numerous unfavourable consequences that are leading to reinforcement of inferiority with respect to their status. In the present existence, there have been formulation of measures and programs that are rendering a significant contribution in bringing about improvements in their status. These have been stated as follows:

- Encouraging towards Acquisition of Education: In rural communities, the system of education is not in a well-developed state. This is primarily characterised by inadequacy in the teaching-learning methods and instructional strategies. Furthermore, the schools do not have well-developed infrastructural facilities, civic amenities, extra-curricular and creative activities and also there are shortage of teachers. These are some of the school factors that have led to a significant decline in the enrolment of students. On the other hand, parents also do not encourage their girls towards acquisition of education as they encourage their boys. Therefore, one of the most significant measures is, girls should be encouraged towards acquisition of education. They should get enrolled in schools and it is the responsibility of the family members as well as the teachers and school staff to ensure that girls are able to attend schools and acquire education safely. During the initial stage, particularly, when schools are located at a distance, then it is the responsibility of the parents to take their girls to schools and bring them back home.

- Augmenting Skills Development Opportunities: Rural women possess keen interest and desire to augment their skills and abilities in terms of various areas. These include production of various types of handicrafts, artworks, music, dancing, singing, sports, physical activities and so forth. In some cases, they are fortunate enough to enhance their skills and abilities in terms of certain areas, particularly, when their parents are involved into them. For instance, when individuals have a family business of pottery making, then they train their children too in this field. Whereas, when girls possess the desire to learn a skill, then their family members should encourage them to get enrolled in training centres. When they are unable to get enrolled in training centres, due to shortage of funds or location at a distance, then normally they acquire training through making use of technology. In the present existence, digital technology has been used comprehensively in rural communities and individuals are making extensive use of it for different purposes.

- Encouragement towards Acquisition of Employment 0pportunities: It has been found that in most cases, rural individuals, especially belonging to deprived, marginalized and socio-economically backward sections of the society give more preference to getting engaged in employment opportunities. The main reason behind is to generate income for the purpose of sustaining their living conditions and it is considered important than any other aspect. Women and girls in rural communities are discouraged from not only getting enrolled in schools, but also in acquisition of employment opportunities, particularly in terms of their interest. Hence, one of the measures to augment the status of rural women and promote empowerment opportunities among them is to encourage them towards acquisition of employment opportunities. In some cases, poverty stricken and underprivileged families even send their girls to urban areas to find employment as domestic helpers. In some cases, when they are fortunate enough to find kind and generous employers, they obtain support and assistance in sustaining better livelihoods opportunities for themselves. 
- $\quad$ Providing Equal Opportunities: Girls and women should be provided with equal opportunities as their male counterparts. When making provision of equal opportunities, the family members need to possess the viewpoint that girls too can promote well-being of their families and carry out same jobs and activities, when they are provided with opportunities. During the early childhood stage, it is vital for the family members to ensure that girls should be sent to schools and get engaged in all kinds of childhood activities. When they grow up, they should be sent to urban communities to get enrolled in higher educational institutions to acquire Bachelors, masters and even doctoral degrees. Research has indicated that when girls are provided with opportunities, then they are able to obtain better career opportunities. In other words, when their families give them freedom to make their decisions and look for means to augment their livelihoods opportunities, then they are able to render an indispensable contribution towards promoting well-being of their families and communities.

- Eliminating Criminal and Violent Acts: The family members within natal as well as in marital homes inflict abuse and mistreatment upon girls, because of various reasons. These are, possession of feelings of antagonism and hatred, when they feel they are too demanding and would not yield any returns on investment, when they do not carry out household tasks and activities in accordance to the expectations, when they are unable to abide by the rules and instructions, when they get engaged in any activity without obtaining approval, when they make use of any item or object without permission and so forth. In most cases, when solutions can be provided to problems in a peaceful manner, individuals impose criminal and violent acts upon women, mainly out of the feelings of anger and frustration. Therefore, individuals need to understand that women too need to be treated with respect and courtesy. They should be allowed freedom, which would enable them to attain empowerment. When they need to convey any information to them or give them suggestions, then they need to ensure that communication takes place in a polite and decent manner.

- Eliminating Discriminatory Treatment: As it has been stated that in rural communities, women and girls experience discriminatory treatment in terms of number of factors, such as, acquisition of education, employment opportunities, participation in skills development programs, health care and medical, diet and nutrition and obtaining other items such as, clothing, playthings, technology and so forth. Families, particularly those who possess limited finances, usually tend to provide better opportunities to the male children. Due to this, girls feel discriminated against within their own homes. Therefore, it is vital for the rural individuals to give equal preference to girls and make provision of essential things to them in order to promote effective growth and development. On the other hand, outside the homes in schools as well as in workplaces too, girls are discriminated against. Discriminatory treatment in terms of payment of wages is common. They are paid less than men, for the performance of same job duties. Therefore, it is of utmost significance to eliminate discriminatory treatment and provide equal rights and opportunities to girls and women in schools, employment settings as well as in making provision of other services.

- Promoting Effective Communication Skills: When girls and women remain confined within the homes and primarily get involved in the implementation of household responsibilities, then they are unable to develop effective communication terms, particularly with individuals, outside the home. In other words, they are unable to realise that outside their home also there is a world, with which they have to interact. They are just able to establish interaction with their family members and do not have any contacts with the community members. Due to this, they possess an apprehensive and reticent nature. Therefore, it is the responsibility of the family members to ensure that their girls participate in various social, cultural and religious programs, make visits to homes of their friends and relatives, and form a social circle. In this manner, they would overcome their reticent nature and put in more confidence in themselves to communicate with other individuals, outside their homes.

- Encouraging Mobility: Remaining confined within the house and having restricted mobility is regarded to have unfavourable effects upon the mind-sets of women and girls. In some cases, they began to experience psychological problems, such as, anger, stress, depression, pressure and anxiety. Due to these psychological problems, they tend to keep to themselves and lose communication terms, even with their family members. Therefore, to alleviate psychological problems and promote effective development of the mind-sets, women and girls should be encouraged towards mobility. Encouraging mobility is referred to encouraging them to make visits to various places. These include, market places, parks, religious places, homes of friends and relatives, health care centres, educational institutions, training centres, and even to other regions and cities. When rural women and girls are encouraged towards making visits to these places, then they are able to benefit in number of ways. These include, development of effective communication skills, generating awareness in terms of various aspects, acquiring academic skills, and promoting good health and well-being, physically as well as psychologically.

- Implementing Morality and Ethics: For individuals, belonging to all age groups, categories and backgrounds, it is necessary to implement morality and ethics. Morality and ethics are 
vital for the individuals to understand, irrespective of their caste, creed, race, religion, ethnicity, occupation and socioeconomic background. When individuals acquire an efficient understanding of these traits, they are able to differentiate between appropriate and inappropriate. These need to be put in operation in the performance of various tasks and activities, as well as in dealing with other individuals. Men and women need to understand the principles, standards, norms, values and ideologies, particularly when they are collaborating with others in the implementation of tasks and activities. When women acquire efficient understanding in terms of morality and ethics, they are able to curb any form of violent and criminal acts and discriminatory treatment that is taking place within the society. Another benefit is, they are able to enhance their status and put into operation, empowerment opportunities.

- Up-gradation of Status of Widows: The status of widows has been in a deprived state. The major causes of deterioration of their status are, they are deprived from many rights and opportunities. These include, prohibition from participating in social, cultural, and religious programs, not permitted to wear coloured attire or jewellery, not permitted to consume various food items, which may include, sugary or fried foods, denied right to property, not allowed to have a say in the decision making matters and inferiority of status. Due to these factors, widows were not able to render an effectual contribution within the society or bring about improvements within their status. Therefore, it is necessary to formulate measures that would bring about up-gradation within their status. In order to lead to up-gradation of their status, the aspects that are of utmost significance are, they should be allowed to express their viewpoints and perspective and have a say in the decision making matters, should be allowed right to property, allowed to participate in various programs and functions and should not be regarded as inferior.

\section{Conclusion}

Within rural communities, women are experiencing number of problems and challenges within the course of enhancement of their status. Women are primarily involved in the management of household responsibilities and in taking care of the needs and requirements of family members. Apart from these responsibilities, their participation has been increased in the informal sector. Factors imposing detrimental effects upon status of women are, poverty, criminal and violent acts, economic exploitation, educational deprivation, child marriage, lack of health care facilities, prohibited from participation in decision making matters, prohibited from participation in other tasks and activities, unequal dis- tribution of wealth and resources and limited visits to other places. Women and girls normally experience one or more of these factors within their households. These are regarded as barriers within the course of bringing about improvements in their status. Hence, it is vital to eliminate these barriers and promote advancement opportunities for women and girls.

In rural communities, the status of women is in a declined state. Preference is given to the male members and girls are regarded as liabilities. The primary factor of bringing about improvement in the status of women is, the family members need to bring about changes in their viewpoints and regard girls as assets. They should make provision of equal opportunities for them and allow to them to get involved in various tasks and activities that would augment their status. There have been formulation of measures to bring about improvements in the status of women. These are, encouraging towards acquisition of education, augmenting skills development opportunities, encouragement towards acquisition of employment opportunities, providing equal opportunities, eliminating criminal and violent acts, eliminating discriminatory treatment, promoting effective communication skills, encouraging mobility, implementing morality and ethics, and up-gradation of status of widows. When rural individuals will acquire sufficient awareness in terms of these measures, then they would render a significant contribution in up-grading the status of women and improving their living conditions.

\section{Bibliography}

1. Bhattacharyya, A. (n.d.). Rural Women in India: The Invisible Lifeline of Rural Community. Bhairab Ganguly College, Kolkata.

2. Yasaswini Y., et al. "Socio-economic Conditions of Rural Women - A Case Study". International Journal of Research and Scientific Innovation 4.8 (2017): 52-53.

3. Chapter II. (n.d.). Review of Women Studies.

4. Anxo D and Lindh T. "Women's Impact on Development in India”. Linnaeus University (2010).

5. Chapter IV. (n.d.). The Status of Women in Indian Society.

6. Chapter - 2. (n.d.). Socio-Economic Status of Women in India: A Review.

\section{Volume 3 Issue 8 August 2019 (C) All rights are reserved by Radhika Kapur.}

